MERCADO $[\mathrm{LS} 22,56,106,109,129,203,230]$

\title{
El mercado divinizado
}

\section{Pedro Pablo Pérez Hernández'}

Palabras clave: bienes, mercado, equilibrio.

Key words: goods, market, balance.

Mots clés: biens, marché, équilibre.

¿Es el mercado un dios? ¿̇los seres humanos estamos sometidos o nos dejamos someter al dios mercado? No cabe duda que la economía mundial está fundamentada en lo que denominamos economía de mercado. La globalización ha provocado que el mercado sea casi único y no existan apenas diferencias entre países, zonas geográficas o territorios; todo se compra y se vende, nada está ajeno a este comportamiento o quizás mejor decir, casi nada. En definitiva, se aplica el concepto de economía, por el que los seres humanos tratamos de satisfacer nuestras necesidades utilizando para ello recursos escasos y susceptibles de usos alternativos sin considerar más opciones que lo que se oferte y se demande. Esta forma de actuar se aplica a los bienes económicos que acuden al mercado, pero, ¿debe aplicarse también a todo tipo de bienes o recursos?

Hay quien considera que el concepto de economía puede ser aplicable también a los bienes que no son económicos, como es el caso de los recursos naturales. Sin embargo, los recursos naturales no son bienes económicos, aunque por desgracia sean tratados como tales. Son bienes libres y por lo tanto no tienen un único propietario, todos somos sus usuarios y como tales, tienen valor de uso (cada vez más

\footnotetext{
${ }^{1}$ Departamento de Economía. Universidad Loyola Andalucía.
} 
elevado por ser recursos cuyo mal uso provoca su escasez y por el tipo de bienes que son, la naturaleza no puede regenerarlos en muchos caso, o se requiere de un elevado periodo de tiempo para su regeneración). El problema ocurre cuando a estos bienes se les introduce el valor de cambio y, por lo tanto, se intercambian sin más en el divino mercado. Este hecho, provoca que su valor se estime por lo que por ellos pueda pagarse $y /$ o ganarse, sin ser conscientes de que su valor de uso es incalculable pues estos recursos son irremplazables por otros bienes y además son necesarios para la vida.

Cuando a un recurso natural, le es asignado un valor de cambio, comienza a escasear por su uso abusivo e inadecuado, de forma que el teórico propietario del mismo o el que ostenta el poder sobre ese bien, no es consciente de que la escasez le afecta a él mismo. Por consiguiente, no todos los recursos pueden ser sometidos al mercado pues puede suceder que se agoten y sin ellos, la vida, con mayúsculas, se acabaría, incluyendo nuestra propia existencia.

El mercado, que no es otra cosa que la forma en la que demandantes y oferentes establecen unas reglas para adquirir y ofrecer sus bienes y servicios, debe estar sometido a la razón, y por ende a la ética humana. El ser humano ha recibido una herencia global en la que los recursos naturales son su más preciado tesoro. Éstos no pueden ser producidos ni reemplazados por otros porque son únicos, no tienen bienes sustitutivos y su ausencia dejaría a otros bienes complementarios sin utilidad para su propio bienestar y subsistencia. Así pues, el mercado debe ser por tanto un instrumento que debe tener límites razonables a su actuación. Y ¿̇quién debe poner los límites?, ¿̇los propios agentes (seres humanos) que en él intervienen?, ¿̇los Estados a través de sus representantes? En cualquier caso, los límites existen y serán impuestos por la propia naturaleza, pero posiblemente puede que entonces sea tarde. Podemos decir que sucede lo que Francisco indica en la encíclica Evangelii gaudium, el desequilibrio proviene de ideologías que defienden la autonomía absoluta de los mercados y la especulación financiera. De ahí que nieguen el derecho de control de los Estados, encargados de velar por el bien común².

Cabría preguntarse, pues, si el hombre con la razón con la que ha sido agraciado estima que debe cuidar o respetar el bien común. La propia teoría económica habla de que quienes consumen y producen deben tener un comportamiento racional, esto es, la razón es la que debe guiar su comportamiento. De hecho, la teoría de la utilidad parte del supuesto que el consumidor es racional, es capaz de determinar

${ }^{2}$ Cf. Francisco (2014) Exhortación apostólica Evangelii Gaudium nn. 52-60. 
sus preferencias y es su objetivo alcanzar la máxima satisfacción posible con su comportamiento. Sin embargo, habría que cuestionarse ¿qué es realmente útile, ¿qué es verdaderamente lo que proporciona satisfacción a la persona? Es necesario considerar que la satisfacción de determinadas necesidades no tiene sentido si debido a ello dejan de poder satisfacerse otros bienes o servicios mayores que afectan incluso a la propia vida.

Debería buscarse entonces un cierto equilibrio para que nuestra forma de vida sea sostenible e inclusiva para todos los seres humanos. Es este otro concepto relevante en la teoría económica: el equilibrio. Es un término que es utilizado para explicar el comportamiento del consumidor (teoría del equilibrio del consumidor) o el de la economía de un país. Así, se elaboró la teoría general walrasiana, que buscaba un equilibrio económicamente estable y socialmente aceptable. Sin embargo, podemos ver que su aplicación en los distintos países y en diferentes momentos, tanto en lo que respecta a la estabilidad, como a su aceptación social, no ha existido como tal o ha durado muy poco. Más bien, las evidencias muestran que se está muy lejos de ser alcanzado tanto en cada país como a nivel global. Valgan como muestra dos ejemplos: el hambre en el mundo sigue siendo una cuestión no resuelta y cuya resolución no se encuentra ni mucho menos cercana, como tampoco tenemos resuelta la necesidad de agua potable para muchas personas. Dos ejemplos vitales para la existencia de la humanidad y cuya sostenibilidad depende de los recursos naturales, su correcto uso y mejor distribución.

Por otro lado, en la segunda mitad del pasado siglo se puso de moda un nuevo concepto asociado al equilibrio: la economía del bienestar, por el cual el equilibrio general se alcanzaba mediante una solución que era óptima para todos. Es cierto que en determinados momentos se ha avanzado en el bienestar de los ciudadanos en general, y en especial los de los países desarrollados. Sin embargo, la economía del bienestar no ha permitido el bienestar real de todos los ciudadanos (con la reciente y profunda crisis económica se ha reducido intensamente el bienestar), y ni mucho menos el de todos los ciudadanos del mundo porque de lo contrario no existirían necesidades básicas insatisfechas. De hecho, la solución dada por Pareto 3 para determinar científicamente dónde se encuentra el mayor bienestar alcanzable de una sociedad: la máxima prosperidad común se obtiene cuando ninguna persona puede aumentar su bienestar en un intercambio sin perjudicar a otra, no se está cumpliendo en absoluto. En realidad, la prosperidad de unos pocos ha venido provocando durante años perjuicios o menor prosperidad para

${ }^{3}$ V. PAReto (1938) Manual of Political Economy, Oxford (Traducción del original francés de 1927). 
otros, pero es posible que si no lo remediamos la búsqueda de la prosperidad sin límites puede tener graves perivicios para todos.

Para mantener el equilibrio de los recursos naturales el mercado no es la solución, ni nunca lo podrá ser. El sistema económico predominante, en palabras del papa Francisco, tiende a fagocitarlo todo en orden a acrecentar beneficios y cualquier cosa que sea frágil, como el medio ambiente, queda indefensa ante los intereses del mercado divinizado, convertidos en regla absoluta ${ }^{4}$. La solución está en sumar la razón y la ética de todos los seres humanos para la sostenibilidad de la herencia recibida. Los acuerdos entre todos los estados de nuestro planeta se nos antojan imprescindibles, como el recientemente logrado en la última cumbre sobre el cambio climático. Algo está cambiando en el interior del ser humano, único lugar que, compartido con otros, puede proporcionar grandes beneficios a todos.

${ }^{4}$ Cf. Francisco (2014) Exhortación apostólica Evangelii gaudium, n. 56. 